THEORIA ET HISTORIA SCIENTIARUM, VOL. VIII, $\mathrm{N}^{\circ} 1$

Ed. Nicolaus Copernicus University 2008

Robert E. Haskell

\title{
The Access Paradox in Analogical Reasoning and Transfer: Whither Invariance?
}

\begin{abstract}
Despite the burgeoning research in recent years on what is called analogical reasoning and transfer, the problem of how invariant or similarity relations are fundamentally accessed is typically either unrecognized, or ignored in computational cognitive science and artificial intelligence. This problematic is not a new one, being outlined by the epistemological learning paradox found in Plato's Meno. In order to understand the analogical-access problematic, it is suggested that the concept of analogical reasoning needs to be reconceptualized as a subset of a higher order domain including the lexical concept metaphor, isomorphic relation in mathematics, the concept of homology in biology, stimulus generalization in psychology, transfer of learning in education, and transposition phenomena in perception, as all share the problem of how invariance relations are generated and accessed. A solution is suggested based on two specific evolutionary and neurological models, coupled with findings regarding the cognitive importance of knowledge-base. The paper constitutes a reciprocal complementarity theory to a previous paper on metaphor, suggesting the neurological origins and a reconceptualization of what are commonly called analogical and metaphorical reasoning. The paper also introduces a higher order form of analogical reasoning called analogical progression. Implications for research on analogical reasoning are discussed indicating the need for a paradigm shift in analogical reasoning research. The paper concludes with a four-stage model of analogical access.

Analogy, and its sister concept metaphor, has disenjoyed a long and controversial history. Indeed, the history and analysis of analogy and metaphor have been traced by authors in virtually every discipline: For example, in psychology Haskell (1987), Hoffman (1980), Lakoff and Johnson (1980), Leary (1990), Ortony (1979), in philosophy Dreistadt (1968), Hesse (1963), Ricoeur (1977), in anthropology Fernandez (1991), and in artificial intelligence Kling (1971), Winston (1978). When
\end{abstract}


I first began to be interested in analogy and metaphor as cognitive phenomena (Haskell, 1968a), analogy and metaphor were basically seen as literary devices to be avoided by "hard" scientists. There were a few notable exceptions in psychology (Asch, 1955, Nash, 1963,) in archaeology (Ascher, 1961) in paleontology (Gould, 1977), in biology and general systems theory (Bertalanffy,1963), in ethology (Lorenz, 1974), in physics (Oppenheimer, 1956) and in numerous other fields. Research in the humanities already had a massive literature on both analogy and metaphor (e.g., Shibles, 1971). Neither concept, however, was conceptualized as cognitive.

Despite a negative prevailing view of psychology and physical and natural sciences during the 1960's, I considered analogy and metaphorical reasoning to be different surface manifestations of a more fundamental set of cognitive processes based on similarity relations generated by a more fundamental underlying cognitive process (Haskell, 1968a) ${ }^{1}$ Accordingly, in addition to analogy and metaphor, I also considered the concepts of isomorphic relation in mathematics, the concept of homology in biology, stimulus generalization in psychology, transfer of learning in education, transposition phenomena in perception, as all based on an "analogical" process, and that analogical reasoning was fundamental to all thinking and reasoning. What I was beginning to conceptualize at that time was that these concepts were based on some kind of invariance relations (See Figure 1) . Over the years, I have been developing a framework for understanding the subserving processes responsible for this array of surface phenomena (see, Haskell, 1968a, 1978a, 1982, 1987b, 1989, 1991, 2001, 2000a, 2000b, see note 6).

The issue this paper will explore, then, involves the fundamental cognitive and neurological process(es) subserving the various surface phenomena indicated above, all of which are here exemplified by the concept of analogical reasoning. Accordingly, when referring to analogical reasoning, this paper will, in fact, be referring to an invariance function subserving the various surface manifestations noted above. More specifically, the paper will address the problem of how this invariance function is cognitively accessed. ${ }^{2}$ Like my article on a neuro functional shift underlying the origin of lexical metaphor (Haskell, 2001 in the special volume of this journal), this paper suggests an integrative cross disciplinary approach is needed. Together these two papers constitute reciprocal complementarity theories on the neurological origins and a reconceptualization of what are commonly called analogical and metaphorical reasoning.

\footnotetext{
${ }^{1}$ Though this article (Haskell, 1968), written as an undergraduate, was an awkward and groping first attempt to outline what I saw at that time was the cognitive significance and scope of application of analogical reasoning. I later developed this view into a masters thesis (Haskell, 1968), and still later into an applied aspect of analogical reasoning (Haskell, 1978b). These early works have been a blueprint that have set my agenda ever since (seen endnote 6).

${ }^{2}$ For purposes of this paper, I will not distinguish between "access" and "retrieval" processes as is often done in the literature.
} 


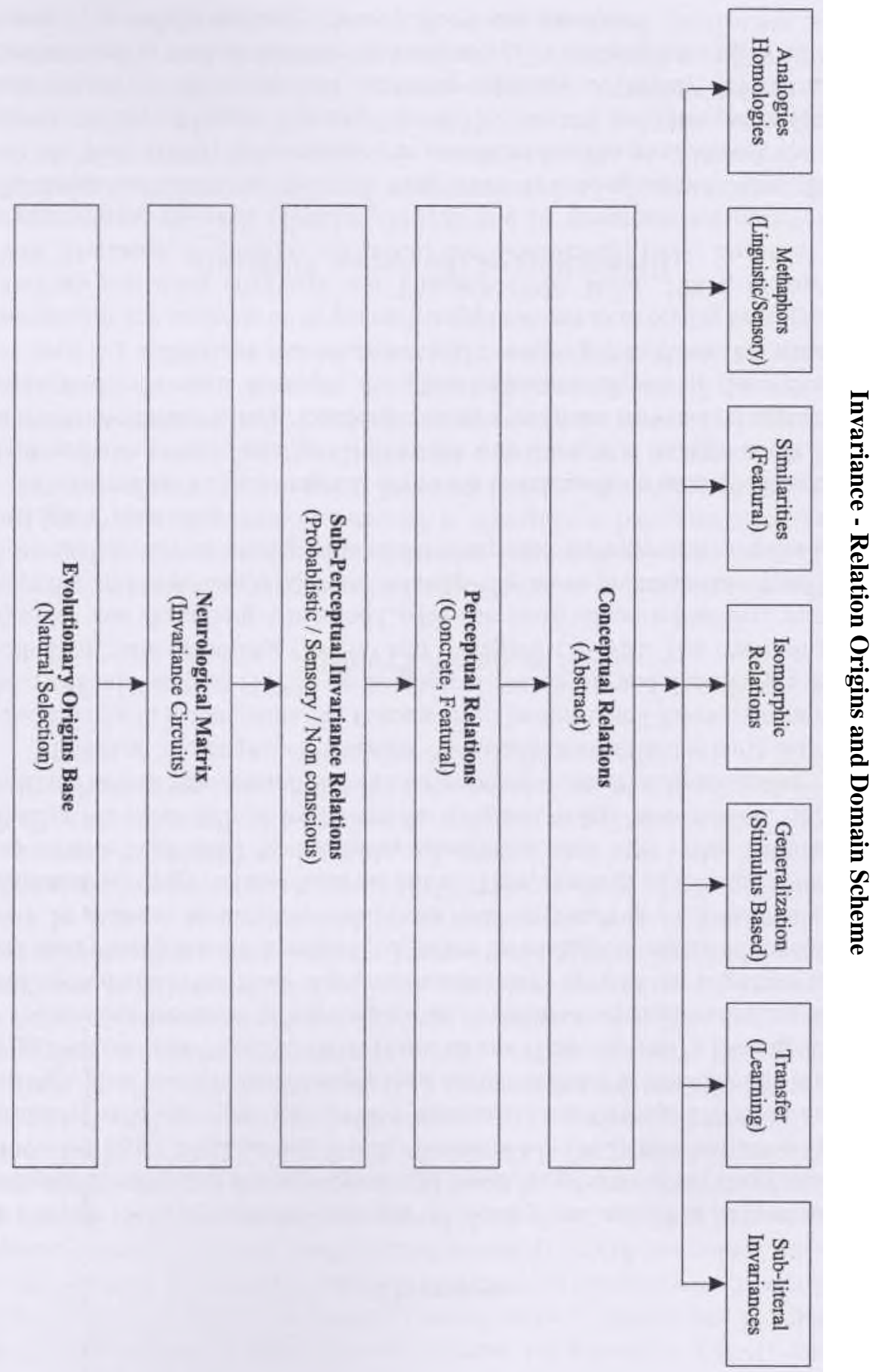




\section{Overview}

In the past twenty years, the concepts of analogy and metaphor have come to be accepted as reflecting not just logical and linguistic properties but deeper cognitive processes (e.g., MacCormac, 1985, Tourangeau, 1982) that somehow involve similarity relations (see, Rips, 1989, Vosniadou and Ortony, 1989). In addition, analogy, et al, are also increasingly seen as fundamental to thinking and reasoning (e.g., Holyoak and Thagard, 1995; Hummel and Holyoak, 1997). During this time, a voluminous literature in psychology and cognitive science, including artificial intelligence and other fields has accumulated with most of the cognitive research and theory being domain-centered (i.e., either on analogy, or metaphor, or similarity, etc.). In addition, historically - and even now-research in each domain area has remained relatively isolated from the others. Thus, research on analogical reasoning has seldom been cited by metaphor researchers, and vise versa. Because each concept has been defined by its surface structure, it has been seen as "different" from the others (the research on similarity being somewhat an exception).

Moreover, the cognitive research on analogical reasoning has been largely conducted with a computational framework. The most well-known perhaps being the work of Gentner (1983) on analogical reasoning and Sternberg's work in both analogical reasoning (1979a) and metaphor (1979b). The research of both Gentner and Sternberg concerned with the analysis of retrieving, accessing, mapping and matching, and more recently alignment processes involved in their work can be seen as paradigmatic of the computational approach to understanding analogical reasoning.

Despite this, a computational approach to research on analogical reasoning, it has led to a virtual paradigm shift in the way thought is thought about, indeed, to a new Weltanschauung: Thinking and reasoning are now nearly equated with analogical processes. Perhaps, the most important aspect of the voluminous research on analogical and metaphorical reasoning has been the widespread recognition and analysis of its pervasive applications to everyday reasoning, e.g.. everyday reasoning (Holyoak and Thagard, 1995, Read, 1983), in law (Levi, 1949, Marchant, Robinson, Anderson, and Schadewald,1991, Sunstein, 1993), organizational research (Tsoukas, (1993) and in governmental policy making (Spellman and Holyoak, 1992 ). In their work on analogical reasoning, Hummel and Holyoak (1997) have noted "our aim is to lay the groundwork for a more general theory of human thinking" (p. 427). Thus the field has progressed from seeing analogy, metaphor, and similarity relations as literary devices to being fundamental to human thinking and reasoning. In this respect, cognitive science seems to be finally catching up with Plato and Aristotle: 
Plato (1956), following his mentor, Socrates, says about reasoning with similarity, "I am myself a great lover of these processes of division and generalization; they help me to speak and to think. And if I find any man who is able to see 'a One and Many' in nature, him I follow, and «walk in his footsteps as if he were a god" (p. 55) Indeed, Plato was so enamored with the idea of reasoning being similarity-based he is said to have written a manuscript (now apparently lost to history) called The Simulacrum. Later we find Aristotle (Cooper, 1960), similarly suggesting: "The greatest thing by far is to be a master of metaphor. It is the one thing that cannot be learned from others. It is the mark of genius" (p. 101). Indeed, in one form or another, the ability at analogical reasoning, cum ability at transfer of learning, has historically been linked to intelligence. For example, Holyoak, Junn and Billman (1984) note that "Analogical thinking is widely, albeit arguably, recognized as a hallmark of human intelligence, and as such the course of its development is a topic of clear importance" (p. 2042). McKeachie (1987) in commenting on paper about transfer research says, "As I read these papers, I could not help thinking of discussions of the ' $\mathrm{g}$ ' factor in intelligence which is characterized by flexibility. Very likely the skills described by ' $\mathrm{g}$ ' include those we have discussed here under the rubric 'transfer'” (p. 711). Shades of Plato and Aristotle.

\section{The Access Problem}

Given the pervasiveness of so-called analogical, metaphorical, similarity relations, generalization, transfer, and other related processes, along with their role in thinking, reasoning, and intelligence, it becomes important to understand how these processes are recognized and accessed. Despite the voluminous research we still do not know how we know that something is the same as something else. Intuitively, it seems simple: we perceive "similarities" between two or more ideas, events, objects. But, counterintuitively, research suggests that featural "similarity" is not the fundamental explanation (see, Rips, 1989).

\section{Recognition of the Access Problem}

From the vast literatures, a few researchers have recognized this fundamental problem of access or how the recognition of "sameness" is apprehended. Mostly the problem is either not recognized or is simply ignored. The problem is this: even given that similarity, relations-however defined-subserve the array of seemingly different phenomena like analogy and metaphor, how is the similarity relation identified? Some quotes by those who recognize this problem is 
testimonial to its importance. Eskridge (1994) recognizes that, "Retrieval of a source is arguably the most complicated issue currently facing researchers in analogical reasoning" (p. 210). And Keane (1987) notes that "one of the most important and least understood questions in analogical problem solving research is 'where do analogies come from ?' or, more technically, 'how are base analogues retrieved?'... explanations of the source of such analogues have been found wanting and in the absence of a better explanation seem largely serendipitous" (p. 53). This is no small matter in understanding analogical access.

Two other well-known researchers, Holyoak and Koh (1987), also recognize that "If two situations drawn from disparate domains have never previously been associated, there can be no direct retrieval pathway linking the two. How, then, might the target activate the source?" (p. 333). Similarly, Spencer and Weisberg (1986 ) note that, "creative discovery is often promoted by noticing an analogy in a remote domain. However, even if one assumes that this view is correct, the question of how these creative discoverers initially noticed their analogies remains open" (p. 448). In reviewing the research on stimulus equivalence, Clayton and Hayes (1999) lament, "We are told that stimulus functions of B are transformed consistent with its mutual relation to A, but we are no closer to an understanding of transformation itself.... a satisfactory description of the process of transfer or transformation is absent" (p. 152). Continuing, they conclude that "If indeed equivalence gives rise to rules, then for a rule to specify a contingency may simply mean that the rule and the contingency are members of the same equivalence class." (p. 149). So this does not solve the problem of access either. Others deal with the problem by considering stimulus equivalence to be an unanalyzable primitive (Sidman, 1990).

As Johnson-Laird (1989) observes, "The processes underlying the discovery of profound analogies are much harder to elucidate than is generally realized" (p. 313), and concludes that analogies "cannot be guaranteed by any computationally tractable algorithm" (p. 313). Again, Holyoak and Koh (1987) recognize that "Particularly in the case of analogies between problems drawn from disparate domains, it is unclear how a problem solver can retrieve a potentially useful source analogue from a large knowledge base. Computational models of analogy have typically evaded this issue, either by explicitly directing the program to compare particular situations ... or by implementing a psychologically implausible exhaustive search mechanism” (p. 332, italics added). deJong (1989), too, asks, "How can a system retrieve a relevant source if it does not already know the 'correct' analogy mapping"? (p. 351). Finally, in asking how someone recognizes a similarity, Green (1979), too, laments that in recognizing metaphorical relations, "I still do not know how they get it... how anyone gets the metaphor." But neither can I explain how anyone "gets the joke," or "gets the parable," or "gets the premise" needed to escape the clutches of 
paradox" (p. 473 ). The solution to the access problem is neither simple, nor obvious. It is, however, an old and venerable one preceding cognitive science. The access problem has been grappled with for over two thousand years in Western philosophy. More specifically in Plato's paradox in the Meno.

\section{The Access Problem and Plato's Paradox of the Meno}

In a critique of behaviorist learning theories, Weimer (1973) framed the problem of recognizing stimulus similarity most succinctly: "How can an organism recognize all the potential instances, on the basis of no prior exposure to them, as instances of the same concept?" (p. 470, italics added). In what should be considered a classic article in cognitive science, Weimer recognized this problem as one of Plato's famous paradoxes. ${ }^{3}$

In his Meno, Plato has Socrates argue "That man cannot inquire either about that which he knows, or about that which he does not know; for if he knows, he has no need to inquire; and if not, he cannot; for he does not know the very subject about which he is to inquire." This is the paradox and problem of accessing an analogy or similarity relation in Platonic terms. In other words, how is it possible that $\mathrm{X}$ is recognized as like $\mathrm{Y}$, or X like X? ? The Socratic "solution" to this paradox is that all so-called new learning is actually remembering something that we already know. This is known as the doctrine of Anamnesis or recollection. While at first glance this apparent paradox may, at best, sound like something from a freshman course in philosophy or a moot academic exercise, in fact, it is one of the central problems of philosophy, education, and indeed, cognitive science.

Since Plato, philosophers, theologians, psychologists, physical scientists, and poets at one time or another, or in one form or another, have grappled with this problem and paradox. Indeed as Pylyshyn (1979) noted some time ago, "Almost every major cognitive theoretician...has had a crack at it." (p. 421). No solution, however, has been generally accepted for Plato's "access" Paradox. It is, therefore, crucial to understand this paradox in relation to analogical reasoning.

Although Weimer, like some others, (Balaban, 1994; Shanon, 1984), question whether the paradox of the Meno, as worded, is a true logical paradox, he recognized that the problem it poses is, nevertheless, a real problem for both philosophy and psychology that must be dealt with if progress is to be made in

\footnotetext{
${ }^{3}$ Being in a largely behaviorist psychology department at the Pennsylvania State University at a time when behaviorist approaches were inordinately influential, despite his penetrating publications, Weimer did not receive tenure. He dropped out of academia, to run a family business. Apparently disillusioned, he would not respond to academic inquiries.
} 
understanding analogical reasoning. ${ }^{4}$ In short, whither invariance? For a more extended treatment of the Plato's paradox in relation to this issue, see Haskell, R. E. (2000b). While this paper will not presume to have logically solved the paradox, it will have a crack at a resolution, suggesting (1) a possible evolutionary basis, (2) a neurological substrate and (3) how, on these biological bases, access can be better understood and therefore initiated.

\section{Transfer of Learning and the Access Problem}

Like analogical reasoning, the instructional concept of transfer of learning is emblematic of the problem of access. Transfer of learning is the use of past learning in learning something new and the application of that learning to both similar and new situations (See, Haskell, 2000a). As indicated above, for purposes of this paper analogical transfer and transfer of learning are considered interchangeable, with the latter being a more general and often more implicit process of perceiving a similarity of some kind. Like analogical reasoning and its other equivalent terms, transfer of learning, too, has had a long history regarding the access problem.

From the very beginning of research on transfer in experimental psychology. Thorndike (1901) explained transfer of learning on the basis of identical elements theory. This theory maintains that transfer of learning only occurs when two situations have identical elements (read, highly similar) in common. If identical elements are not present, then, no transfer of learning will take place (except by sheer contiguity). Thorndike's view of transfer has held sway in educational theory ever since. Modern cognitive research on analogical reasoning and artificial intelligence is also based on Thorndike's 1901 identical elements view. Singley and Anderson, two well-known cognitive scientists (1989) in their seminal computational theory of how we acquire skills make it clear that.

The essence of this book is that Thorndike's identical elements theory is alive and well in a new body. We have resurrected Thorndike's theory by redefining his identical elements as the units of declarative and procedural knowledge in the ACT*

${ }^{4}$ Although Weimer, like others (Boom, 1991; Calvert, 1974; Moline, 1969; Rohatyn, 1974: Sim 1976) have questioned whether the paradoxes of the Meno, as worded, are technically logics paradoxes, he argues that the learning paradox is a serious conceptual problem for both philosophy and psychology and that its resolution must be dealt with by both disciplines. Shanon (1984) addressed the Meno from a cognitive psychology perspective, but he did not address the resolution of the paradox. Using cognitive psychology findings, his approach was to address the issue of whether the paradox as stated by Plato was in fact a paradox. His conclusion was that it was not. 
theory... The key difference between his proposal and ours is that, whereas Thorndike's elements referred only to external behaviors, ours include purely cognitive operations that reference abstract mental objects (p. 248).

The authors have not in fact resurrected Thorndike's theory-since it never diedbut have recast it in modern computational language.

In much of computational cognitive science, the view of how general concepts are constructed has not changed from the time of Aristotle. Following Aristotle, Singley and Anderson, in explaining how generalization works in their computational system say that it, "is done by abstracting common features of the source and target of the analogy" ( $p$. 31, Italics added). Aristotle's attempt to solve Plato's notion of universal concepts by positing abstract categories based on "common" features merely eliminates the problem of access by defining it away since claiming "common" features already assumes similarity relations. Further, Singley and Anderson (1989) clearly state, "Conspicuous by its absence in this discussion is any mention of the...mechanisms of generalization and discrimination which create new productions by inductive, syntactic transformations....processes of generalization and discrimination do not figure in our analysis of skill acquisition....we have nothing new to say about this type of transfer in this book" (p. 50, italics added). These two major figures reflect the more general state of affairs in cognitive science regarding this fundamental problem of access.

With some exceptions, then, nearly the entire history of research on metaphorical and analogical reasoning in the humanities, philosophy and in psychology has been dominated by the idea that analogies and metaphors are accessed by similarity relations of some kind (concrete, abstract, sensory, etc.) despite the concept of similarity itself being known to be problematic for some time both logically (See Goodman, 1952; Quine, 1953) and cognitively (Rips, 1989, Shanon, 1988). And Medin and Ortony (1989), "agree with Rips that, unless one can specify how similarity is determined, the resemblance approach to similarity is vacuous" (p. 188). I will address Plato's paradox in more detail below. At this point it is necessary to look in somewhat more detail at the current state in cognitive science with respect to the problem of analogical access.

To reiterate: While the look of similarity has changed from referring to the concrete features of things to abstract conceptual relations and to procedural or computational production sequences, similarity - in one form or another- remains the primary explanation. From Edward Thorndike's influential identical elements theory of transfer, up through the contemporary computational cognitive science and information processing literatures on analogical transfer, then, similarity remains the default position for explaining analogical transfer and, by implication, Plato's paradox. 
The question now is: how are identical elements and similarity recognized? Briefly, the classic answer has been Aristotle's: by abstracting out the common features from an array of stimuli, despite long standing research to the contrary on categorization processes (e.g., Rosch and Mervis, 1975). According to this abstraction view, categories are constructed by the increasing predominance of the similarities among stimuli over their differences. The process of abstraction subtracts from an array of the relevant attributes, which are defined in terms of similarity. Thus the theory presupposes in its explanation what it proposes to explain. Shades of Plato paradox, once more. As I have briefly noted (Haskell, 1997) elsewhere, "Though there is a great deal of research on cues, systematicity, and other apparent routes into "recognizing" similarity, what computational models, in fact, actually do is to tell us how we process a similarity relation after we have already recognized or accessed it" (p. 92).

\section{Computational Approach to Analogical Reasoning}

Such computational research on analogical reasoning and transfer holds that accessing an analogy is largely based on searching and finding a similarity and then mapping and matching, and more recently aligning the similarity between the two parts of the analogy. Thus, the obvious and conventional approach to how an analogy is initially recognized is that the brain rummages around its memory stores in search of a similarity and finds a "match."

One influential computational model of analogical reasoning is Gentner's (1982, 1983, 1988, 1989), analysis of the well-known analogy between the solar system and the atom. The research by Gentner purports to explain analogical transfer but being based on similarity relations - whether concrete or abstract - does not address the paradox. Markman and Gentner (1993), however, propose an interesting perspective on the concept of recognizing similarity. Instead of dealing with individual featural similarities, they assume similarity resides in a set of systematic alignments of all features between an analogy. Accordingly, similarity resides in an isomorphic matrix (my term, not theirs) alignment, or structure-mapping, between source and target, $\mathrm{X}$ and $\mathrm{X}$ '. For example, given source characteristics $X_{1437}$, target characteristics must have the same alignments. $\mathrm{X}^{\prime}{ }_{1437}$ They can not be $\mathrm{X}^{\prime}{ }_{1743}$, While this is a most interesting advancement, it merely adds another step in explaining of how similarity is established. It does not change the problem of access as it, again, assumes what it later purports tc show-similarity; it merely switches the burden from individual features to a systems alignment. Though the concept alignment is itself important, this view of similarity compounds the problem. 
A variant of a strict computational approach to analogical reasoning is the work of Holyoak $(1985,1987,1989)$ who emphasizes plans, goals and other cognitive constraints in accessing analogues. This view is not so much interested in the mechanisms underlying analogical reasoning as it is in the multiple constraints imposed on the reasoning process, i.e., its use. For example, problem space constraints, purpose or plans of use, etc. While quite aware of the problem, Holyoak's approach does not solve the access problem either.

In addition to the historical and voluminous research on the function of similarity relations in accessing analogical transfer, other techniques like giving hints (e.g., Gick and Holyoak, 1980), cues (Gick, 1985 ), and use of metacognitive strategies (Gray, 1991, Nickerson, Perkins, and Smith, 1985) — while useful in other respects — do not address the fundamental problem or paradox of access. Still another approach in artificial intelligence is the use of an abstract plan and other conceptual features that are used to index the source of analogy. But as deJong (1989) points out "Any example of the source would be stored under these conceptual indexes"(p. 351) and therefore, again, assumes what it later purports to explain as similarity relations are built into the indexing.

\section{Brief Critique of the Computational Approach to the Access Problem}

Thus, neither strict computational approaches in cognitive science nor other artificial intelligence approaches add anything of significance to explaining analogical access. In fact, it could be said that other than as a systematic heuristic, the analysis of mapping, matching, and alignment of analogical components has yielded little of consequence that has not been known previously by philosophers, those in the humanities, and by other non computational research analyzing and applying analogical reasoning.

Computational approaches have essentially contributed only a set of abstracted algorithmic-like steps for processing analogical reasoning e.g., accessing, retrieving, mapping, matching, and alignment, by which to analyze how subjects' reason about and "retrieve" an analogy after the fact. Just as Weimer recognized that this approach does not solve Plato's learning paradox, so, too, Koestler (1967) understood that in similar learning theory explanations, there is a "ghost in the machine."

This brief critique of the computational approach to analogical reasoning and access is not meant as a broad sweeping indictment. Certainly for certain heuristic and pragmatic purposes computational listings of presumed systematic steps involved in analogical reasoning have been useful, just as a listing of the 
problem solving procedures in medical emergency manuals are useful. But it needs to be recognized that such computational lists are simply like a "911" operating manual for analogical reasoning. Accordingly, just as for everyday purposes the concept of similarity is often useful, so, too, are computational analyses, but as a fundamental explanation for explaining the access problem they both fail. ${ }^{5}$

Finally, almost by definition, most of the computational approaches to analogical reasoning-connectionist models notwithstanding - are, of course, based on the assumption that the brain functions like a computer. Thus, all such artificial intelligencelike computational programs and systems for analogical reasoning operate on programs that already have built into them "recognition" algorithms for accessing the analogy or similarity relation. Perhaps what Jerry Fodor (1980a), concludes about computational and artificial intelligence approaches is appropriate here. Says Fodor, "People who do machine simulation, in particular, very often advertise themselves as working on the question of how thought (or language) is related to the world. My present point is that, whatever else they're doing, they certainly aren't doing that" (p. 65 ).

I point all this out, in part, to support the fact that cognitive science research on analogical reasoning and transfer has not only remained provincially cloistered from the vast philosophical and other non computational literature, but from the long line of research on the other similarity-based concepts indicted in this papers. Quite frankly much of the research has become repetitive, uninteresting and firmly engaged in what Kuhn (1970), describing scientific revolutions, has called "normal science," where after a paradigm shift the drudge work on details conducted. Accordingly, the normal science approach in analogical reasoning research has been merely tweaking minor issues. The problem is that there was never a prior paradigm shift, or revolution, from what basically has been and largely remains a "folk" conceptualization of analogical reasoning.

I point all this out, too, in hopes of generating integrative research and theory based on a more fundamental paradigm leading to a broader spectrum of what is typically conceptualized as "analogical" processes. Just as juxtaposing two metaphors-al la Black's (1962) interactive view of metaphor — often leads to new insights on the target and/or source, bringing together the seemingly different concepts of analogy, metaphor, isomorphism, transfer, etc., will likely lead to

\footnotetext{
${ }^{5}$ The problem with most U.S. cognitive science as it relates to analogical reasoning is not just its componential approach, but also its dedication to the use of experimental design to the exclusior of all other methods. The problem, however is not componential and experimental designs per se. but with their exclusionary nature that casts suspicion on all other methodological approaches. In any event, with the unfortunate exception of textbooks on learning and cognition, the componential approach seems to be reaching the end of its explanatory power for everyday reasoning.
} 
new insights, hypotheses, and research. A broader and integrative approach will undoubtedly generate new hypotheses to be investigated by both experimental and non experimental methods. For example, see my concept below of analogic progression, a higher order continuous form of what is currently called analogical reasoning. ${ }^{6}$

\section{Are Analogical Reasoning Findings Constrained By Literacy?}

A final problem similar to one examined in my article (Haskell, 2001) on a neuro functional shift underlying the origin of lexical metaphor (in the special volume on metaphor of this journal) remains. That article argued that the prevailing view of lexical metaphor as a figure of speech is the consequence of an inappropriate cognitive turn that resulted in a superimposition or back scanning of a modern alphabetic/literacy-based epistemology on to a linguistic phenomenon originating in a preliterate or oral culture. In that article, I suggested that lexical metaphor was originally not a linguistic figure-ofspeech derived from literal language but only later came to be so conceptualized as the consequence of a neurofunctional shift (NFS) in hemispheric laterality, a shift precipitated by the invention and adoption of the Greek vocalic alphabet.

It is generally accepted that most of the cognitive science agenda can be directly traced back to Greek philosophy (Gardner, 1985). More specifically, Le Doux, (1996) notes, "Cognitive science resurrected the Greek idea of mind... as a carefully engineered machine [which] seemed more appealing than the idea of the mind as a biological organ with an evolutionary history" (p. 39). Being a modern variant of Aristotlean logic which was developed as a philosophy hundreds of years after the adoption of the Greek vocalic alphabet

\footnotetext{
${ }^{6}$ For some years now I have been developing an applied linguistic and cognitive framework with a structural methodology for analyzing verbal narratives that are based on the "analogical invariance" relations described in this paper (Haskell, 1991, 1989, 1982, 1978). For purposes here, suffice it to say that I have found in my small group dynamic laboratory where there is a one-way vison mirror, or tape recorder and (even when aware of both) discussants will select into conversation stories about the CIA or FBI, secrets, and wiretapping. These literal topics and stories I have repeatedly found to be "analogical" expressions of members' affective concerns about being watched or recorded. Discussants have no conscious recognition of why these stories were selected into the conversation. Somehow non conscious affective concern schemas cue linguistic schemas that then generate literal linguistic selections that in fact are analogues of what is occurring in the group discussions. While these stories are otherwise literal, they isomorphically map onto the group situation, where stories about $X$ have what I have called sub-literal meaning $\boldsymbol{X}^{\prime}$. Such findings call into question the very definition of what constitutes literal v. metaphoric, analogical or figurative just as does the parable, the pun and the double entendre.
} 
had became interiorized (see, de Kerckhove, 1986; Havelock, 1963, 1983, Skoyles, *1984), it follows that computationalism inherited Aristotle's post oral-age and literacyderived epistemology that has likely distorted the investigation, understanding of analogical reasoning and access. In short is much of what is known about analogical reasoning and access an artefact of this epistemological cognitive turn?

Perhaps beginning with the work of Luria (1976) who found that populations lacking in literacy engaged in a quite profoundly different form of thinking from those who are literate. More recently, Chernigovskaya, (1994) suggests a cerebral laterality difference between literate and non literate subjects as well. So not only are computational and Aristotelian approaches to research on analogical reasoning not compatible with evolutionary and neurological data, many findings may likely be congruent with only a literate population. If so, then as argued in the opening of this paper a broader more interdomain and interdisciplinary formulation, one that requires a paradigm shift from the field's current "folk" conception of analogical reasoning and access.

\section{Resolutions of the Access Paradox}

As indicated above, over the years Plato's paradox has been recognized in one form or another by major researchers in cognitive science (Simon, 1976, Shanon, 1984, Weimer, 1973), developmental psychology (Boom, 1991), and in philosophy and other fields, (Rohatyn, 1974, Moline, 1969, Calvert, 1974, Balaban, Oded. 1994). A number of attempted solutions have been advanced, none of which have solved the problem (for a more extended description, see Haskell, 2000b). For example, one all too obvious solution to Plato's paradox is to divide knowledge into conscious and unconscious knowing. Thus, though we may not know consciously, we may know something unconsciously. Plato, of course, did not have our modern language of conscious and unconscious. Polanyi (1967) implies that the paradox can be resolved by resorting to unconscious knowledge which he calls "tacit" knowledge.

Similarly, Haslerud (1972) considered the discovery of similarity a post hoc reaction when an individual intuitively feels that something is familiar or similar but which may not reach a level permitting conscious verbalization of it. Schor. (1963) recognized that ,people have been trying to explain the emergence of new concepts for over two thousand years." He advances a similar unconscious explanation for how we can inquire about something that we do not know about He says that we intuitively feel what he calls an "intimation" of a similarity relation based on our store of knowledge. While having unconscious knowledge allows us to know more than we can consciously know or inquire about, this 
solution - as unconscious is commonly understood - only postpones Plato's paradox; it merely pushes the paradox back a step.

Johnson-Laird (1983), maintains that his theory of mental models solves the cognitive paradox. His attempt to solve it by claiming that the paradox rests on false assumptions does not solve it; it eliminates the paradox. More importantly, however, he claims that reasoning with mental models relieves the dilemma. In fact reasoning with mental models itself is based upon the a priori apprehension of similarity between the model and what the model is a model of. More systematic resolutions to the learning/access paradox have been suggested.

\section{The Philosophical Nativists Resolution}

As might be expected, philosophers have applied their trade to cognitive science and have entered the education arena as well. In both fields they continue to grapple with the ancient problem posed in the Meno. The history of Western philosophy might well be characterized as the hunt for the origin of the link between the abstract or universal concept, and its particular instances, and thus essentially the resolution of the learning paradox of the Meno. The psychologist and philosopher Hoffding (1893, 1905a, 1905b) wrote extensively on this problem, though he did not mention the Meno. He says,

There are typical or general ideas, only in the sense that we can make a concrete individual idea serve as an example or representative of a whole series of individual ideas. The generality of an idea will, then, mean nothing more than its fitness to be employed as example or representative. But it still remains to be asked, What is the psychological process by which an idea comes thus to be set up as representative? (1905a, p. 166, italics added)

The unexplained psychological process or missing step by which an idea comes to be set up as representative (read: similar to) has become known as the Hoffding Step $\backslash$ it is the contemporary analogue of the learning paradox of Plato's Meno. The Hoffding Step leads Weimer (1973) to maintain that "in so far as we are 'directly' aware of anything, it is universals rather than particulars" (p. 30). In this view, it is the universali.e., representativeness or similarity-ness - that enables the perception of particulars, not the other way around. But where does this abstract representativeness come from? Plato's question remains extant.

Fodor (1980b), takes cognitive science head on and comes down on the side of the Meno, giving the learning paradox new life. Like Plato's resolution of innate memory and recollection, Fodor maintains that humans are bom with knowledge that allows them to "re-cognize" novel events. Fodor doesn't deny 
the reality of everyday learning, however. Concerned with the issues surrounding "new" concept (and cognitive stage) learning which he believes to be a confused notion, his claim is that all learning theories are based on flawed premises and that there can be no such thing as "new" concept learning.

Fodor agrees that complex concepts might be learned because they can be initially represented by other more primitive concepts, maintaining that initial mental structures are powerful enough to generate apparently new concepts only to the extent that they do not exceed their own conceptual boundaries - in which case, they have not created anything "new." Further Fodor (1980b) says that a theory of learning "must be a theory of how the environment selects among the innately specified concepts. It is not a theory of how you acquire concepts, but a theory of how the environment determines which parts of the conceptual mechanism in principle available to you are in fact exploitec $T$, (italics added). Thus in Platonic terms, the structure for learning language is recollected, i.e., retrieved from "memory," as it were. This epistemological view is known as nativism, which holds that all fundamental knowledge inherently resides within the individual.

Fodor (1980b) further says, "It seems to me that there is a sense in which there isn't any theory of learning... [and] ...that in a certain sense there certainly couldn't be; the very idea of concept learning is, I think, confused" He goes on to say, "anybody who has ever given a theory of learning in terms of mental processes (anybody who has ever said anything about what the information flow [...read: computational...] in learning is like) has said, in effect, that learning is a matter of inductive extrapolation, that is, of some form of nondemonstrative inference" [(p. 144-145) italics added]. As Gardner (1985) comments, Fodor's claims are in deadly earnest and even though his cognitive claims have failed to persuade most of his cognitive science colleagues, they have proved difficult to undermine. At their bedrock level, learning theories, then, are based on transferring what we already know. So the learning paradox of the Meno-and therefore the accessing of analogical transfer-remains intractable after more than two thousand years.

\section{The Biological Nativist Resolution}

If there exists innate learning structures, as Fodor suggests, then they must have evolved through millions of years. Enter evolutionary approaches to the learning paradox of the Meno - and to the problem of analogical access. Despite recent abuses, evolutionary psychology has valid roots (see Campbell's 1960 classic article that Popper 1987 has said is "a treatise of prodigious historical learning there is scarcely anything in the whole of modern epistemology to compare with it" p. 115). Popper and Campbell are both known for spearheading what is callee 
evolutionary epistemology which holds that, "The main task of the theory of human knowledge is to understand it as continuous with animal knowledge; and to understand also its discontinuity - if any-from animal knowledge" (p. 115). More recent work is perhaps exemplified by Plotkin (1997, 1994) and Cummins and Allen (1998). Computational approaches tend to be divorced from any biological base (see below).

Now, if cognitive science is stuck with Plato's paradox, then it is likely we are stuck with Plato's Anamnesis or recollection resolution, or some variant form. For most scientists - cognitive and otherwise-Plato's doctrine of anamnesis or recollection appears to be a totally absurd doctrine. But is it possible to resuscitate the doctrine of anamnesis in anything resembling Plato's original form? Weimer (1973) believes the answer is "yes," the doctrine of anamnesis can be resurrected if we understand what the doctrine requires, and what it was designed to accomplish. He suggests that the Plato's doctrine "requires ... priori knowledge that transcends any given individual's lifetime and experience." (p. 28) To reinstate the doctrine of recollection, we need an a priori mechanism (in the sense of innate) competence, knowledge in the sense of capacity, rather than specific content. If such did exist, it would have to have evolved.

Weimer pointed to a neglected book in psychology by a Nobel Laureate in economics turned psychologist, Hayek (1952). Hayek was concerned with perception, and the physiological correlates of our psychological abilities. Briefly, his thesis is that no sensory input is "perceived" unless it is perceived as one of the kinds of inputs already accepted by the nervous system, that is, analogous or isomorphic inputs. Says Hayek, "An event of an entirely new kind, which has never occurred before, and which sets up impulses which arrive in the brain for the first time, could not be perceived at all" ( $p$. 142). Put another way, unless inputs are "isomorphically" accepted as a match to something already in our nervous system that has been acquired in the course of the development of the species and the individual by a kind of "experience" or "learning" on a species level, we don't perceive it (For example, it is clear that we don't have the necessary biological apparatus to perceive X-rays and most other electro magnetic wave lengths).

In Hayek's words, "we do not have sensations which are then preserved by memory, but it is as a result of physiological memory that the physiological impulses are converted into sensations" (italics added, p. 53) That is, nothing comes into our mind unless it matches what we already have in our mind. Hayek sees transfer as being hardwired into our neurological system. Under a heading entitled "The Nervous System as an Instrument of Classification," Hayek says, "A wide range of mental phenomena, such as discrimination, equivalence of stimuli, generalization, transfer, abstraction and conceptual thought may all be interpreted as different forms of the same process of classification which is operative in creating the sensory order" (p. 16). As Weimer insightfully 
recognized, Hayek's psychological thesis is literally Plato's doctrine of anamnesis in modern evolutionary and neurological dress. Is there any empirical evidence suggesting that this rather strange and ancient doctrine of Plato's might exist in some modern form, and thus address the analogical access problem?

\section{The Biological Evolution of Selection Schemas}

While, for certain purposes cognitive science has achieved considerable success in understanding the mind as an abstract information processing and computational system, because it has been abstract and formal, it has tended to lack actual nervous system instantiation. As Chiarello (1991) has observed, "Because our brain is the result of evolutionary pressures that select for biological fitness and reproductive success we can expect that the human mind will have some design features that may not be predictable from an information engineering standpoint" (p. 251, italics added). Concluding she says "the most elegant model of some cognitive process, even if it predicts a range of behavioral data, may not be the right model unless it is also neurologically plausible" (p. 251). In agreement with Chiarello, Kosslyn and Koenig (1995) have called for a "wet mind" approach instead of a "dry" computational one.

If it is the case that evolution has hardwired an invariance function into the brain that subserves analogical access, then what is needed to explain how a hardwired invariance module or set of circuits might work is not current computational (as understood in the analogical reasoning literature) "software" but what Kosslyn and Koenig (1995) have called a "wetware" approach to understanding how the brain works. For analogical transfer in its many manifestations to be so fundamental and so pervasive, it must have evolved a neurological substrate through natural selection (see below). What most language theories and computational approaches to analogical transfer lack is a compatibility with evolutionary principles and neurological findings.

Almost certainly since the brain has not essentially changed for a hundred thousand years - long before most theorists believe complex language came into being - any neurological substrate would not be language specific, but rather for language as a byproduct of some other adaptation (see, Chomsky, 1972; Gould and Lewontin, 1979). Though not all are in complete agreement (see, Pinker and Bloom, 1990), it has been increasingly suggested by others in various fields (Kimura and Archibald, 1974; Chiarello, 1991; Edelman, 1989; Kosslyn and Koenig, 1995; Springer and Deutsch 1981; see Haskell, 2001) that the left hemisphere capacity for language did not evolve for language (a la syntax) per se, but is an adaptation built on an already existing complex set of motor sequencing functions. 


\section{Edelman's Immunological "Analogy”}

Perhaps the most fascinating evidence for a nalivistic view of how new knowledge is acquired, comes from the work of two Nobel Laureates in immunology (See, Jerne, 1985, Edelman, 1987, 1992). Jerne and Edelman believe that the immune system is a kind of hermetically sealed system that contains all of the possible responses to the external antigen world. Our immune system does not directly learn from the external world but instead "recognizes" the vast array of possible antigens. Even "more astonishing," says Edelman (1992), "is the fact that a specific recognition event occurs even for new molecules synthesized by organic chemists, molecules that never existed before either in the responding species or in the history of the earth for that matter" (p. 75). Here we have a kind of modern Platonic doctrine of immunological "recollection" or anamnesis. Based on this framework, Edelman (1992), like Fodor, takes on cognitive science. He says,

the cognitive science view of the mind based on computational or algorithmic representations is ill-founded. Mental representations that are supposedly syntactically organized fin a 'language of thought') and then mapped onto a vaguely specified semantic model or onto an overly constrained objectivist one are incompatible with the facts of evolution, (p. 152 ).

Edelman bases his critique of the cognitive science model of learning on his immunological research.

Now, what is significant here for a nativist view of learning and knowledge acquisition — and by adaptation, for a resolution of the access problem — is that both Jerne and Edelman have suggested that the human brain works like the immune system; that so-called learning by instruction is really "recognition." By recognition, Edelman means, "The continual adaptive matching or fitting of elements in one physical domain to novelty occurring in elements of another, more or less independent physical domain, $a$ matching that occurs without prior instruction" (p. 74, italics added). The question is, is there any evidence that this "analogy" or parallel between the immune system and the brain is more than that: a simple analogy. What makes Edelman's hypothesis that the brain works like the immune system more than just an analogy is the following startling discovery: In terms of embryological development, says Edelman, "my colleagues and I were excited to discover that neural cell adhesion molecules or 'brain glue' are the evolutionary precursors of the whole immune system" (p. 79 ) It appears that our brain and our immune system are evolutionarily and embryonically connected.

Edelman goes on to say "In considering brain science as a science of recognition I am implying that recognition is not an instructive process. No direct 
information transfer occurs, just as none occurs in evolutionary or immune processes. Instead recognition is selective." (p. 81). Just as in evolution and in the immune system model, information is selected, not learned or acquired through instruction. It should be noted that Edelman's selectionist view of "new" ideas is also compatible with Campbell's (1960) classic evolutionary theory of creative thought in psychology. In agreement with Edelman, Gazzaniga (1992) rightly concludes that "If, indeed, selection theory does operate at the higher level of "whole-brain" processes, we must seriously rethink our current conception about the nature of psychological processes" (p. 5).

It would seem that the philosophical rationalism and nativism view of mind and Plato's learning paradox has a scientific base. But while Plato may have scientifically come of age, has cognitive science learned anything new that Plato didn't already say? Weimer concludes that "In 20-odd centuries we have managed to learn nothing at all "new' about the nature of knowledge and learning. And that does not augur well for the future of psychology. Perhaps we are doomed to have a (tolerably efficient) technology of behavior modification, but no science of knowledge and learning at all" (p. 32). This is not to say, however, that useful everyday knowledge of learning has not been acquired. Indeed, the findings of cognitive science have been useful in helping to understand the mental technology involved in some reasoning, thinking, and learning processes. But, again, only once the "new" has already been discovered, recollected, or recognized.

While Plato's learning paradox and Edelmans's evolutionary selectionist view of learning via his parallel between the immune system and the brain are fascinating, is there any similar neurological evidence that might explain Plato's learning paradox and how analogues are accessed?

\section{The Evolution of the Neurological Architecture of Invariance}

The question now is, is there evidence suggesting a neurological substrate for invariance relations? Happel and Murre's (1994) work can be applied to the problem of "similarity" relations and to analogical access. They suggest on the basis of their simulation of neural networks that the hardwired architecture of our brain is the result of a long evolutionary process during which a large set of specialized subsystems evolved interactively to carry out the tasks necessary for our survival. They also suggest

that the evolutionary directives encoded in the structure of the brain may extend beyond merely an increased ability to learn stimuli necessary for survival. We propose that the initial architecture is not only important for rapid learning, but that it also induces the system to generalize its learned behaviour to instances not previously 
encountered. Generalization of learning may well be a principal function of much of the initial structure of the brain (p. 1000, italics added).

Generalization of learning is, of course, just another way of describing a kind of (micro) analogical transfer. These findings, too, can be seen as suggesting that the foundation for analogical transfer has apparently been laid by evolution and is directed at increasing the chances of survival for all species.

It appears that these neurological structures have evolved on the basis of several principles. Happel and Murre claim that in addition to hierarchical and global organizational systems, there are highly regular structures at a more microscopic level in the form of neural modules containing as little as a hundred cells, known as mini columns. These mini columns have been proposed as the basic functional units of the cerebral cortex, the part of the brain largely responsible for reasoning. Happel and Murre (1994) note that the structure of these pathways is similar (i.e., analogous) to the broad division of the primate visual system into two principal pathways: One pathway processes visual input in a coarse manner and has a fast response time, the other pathway carries out a much more detailed analysis and is much slower at processing input (p. 1000, italics added). This two stage process will become important in a moment.

Happel and Murre further suggest that learning from examples can be viewed as a method to reduce the intrinsic entropy or disorder in the system by excluding non relevant connections that are incompatible with a learning set (entropy is the disorder or randomness in a system; in information theory entropy equates to "noise," or random errors in a transmission). ${ }^{7}$

\footnotetext{
${ }^{7}$ In the opening of this paper, I indicated that the concepts of metaphor, isomorphic relation, homology, stimulus generalization, transfer of learning, and transposition as variants on a fundamental "analogical" process. There is (at least) one more concept to add to this list: the "example." Examples are not typically seen as "analogies," but it is important to see them as such, especially given their significance established by the considerable research in transfer of learning in schema induction. Examples, are not seen as analogies largely because an example is said to belong to the same class, category, or domain of what it is an example of. Those who emphasize the role of similarity are more likely to consider the example, though even then it is not seen as an "analogical relation" but as on a similarity continuum. For example, Rumelhart (1989) observes that, "it is possible to see a continuum of possible situations for reasoning by similarity involving at one pole what might be called remembering and at the other what might be called analogical reasoning. In between, we have such processes as generalizing, being reminded, and reasoning by example"(p. 301). An example that is seen as crossing a class, category, or domain has been considered a "catetory mistake," to use Ryle's classic (1953) view. However, since nothing is ever absolutely the same as anything else, when we create an example or see something as an instance of something else, we are generalizing by focusing on the similarities between the example or the instance and the general category we consider them to be instantiations of. It follows then that when we use examples and instances of an event, we have already engaged in analogical reasoning with implicit mapping and matching processes. Category mistakes assume that classes and domains are "natural kinds," which they are not. Inter domain and intra domain
} 
Effective extraction of rules from examples must be directed at locating mappings in the network that are compatible with the entire task domain rather than just with the encountered examples. Such mappings are said to generalize well from the learning situation to the task situation. In general, then, the extraction of effective rules is likely to occur if the summed probability of all internal network configuration connections is high. Thus, say the Happel and Murre,

If the architecture prohibits the formation of undesired mappings, learning is greatly facilitated and the network will generalize well....This would explain why for many vital learning tasks only a minimal exposure to relevant stimuli is necessary. Evolution coarsely programs the brain to function in specific task domains. Learning completes these neural programs by fine-tuning the connections and dynamics. The combination of an initial architecture produced by evolution and experience-based additional finetuning prepares the organism to function in an entire domain, rather than just the limited part of the environment to which it was exposed (p. 987, 1000, italics added).

Happel and Murre go on to conclude that if the above is an important underlying principle of learning, then it must be concluded

that the hidden structure of the brain may capture many more regularities of the world around us than we have expected so far....The main conclusion that can be drawn from the above two experiments is that an initial modular architecture can induce a system to better generalize its learned behaviour to instances never encountered before (p. 1000, italics added).

It appears, then, that the brain may have evolved to function largely on the basis of innate invariance-or generalization-relations, with innate modules designed for quick recognition of surface similarities which are then later processed by specific learning. Why this mechanism evolved may be due to its survival characteristics. ${ }^{8}$ Certainly it's a simple enough mechanism that even the lowest of species can utilize to some degree.

\footnotetext{
${ }^{8} \mathrm{~A}$ reason for our propensity to focus on surface similarity is that there seems to be a positive correlation between surface similarity and deep important underlying structural similarity. That is, surface similarity is sometimes a good indicator of deeper kinds of transfer. First-glance similarities are fast evaluations that are often needed to avoid danger. In evolutionary terms, if it looks like a hungry tiger, prowls like a hungry tiger, and growls like a hungry tiger, not only is it probably a tiger, but in terms of the probabilities, we damn well better assume it's a hungry tiger. Evolutionarily speaking, facing the consequences of a invalid surface similarity is typically not as serious as ignoring a valid one. In short, it may have more survival value to assume that a surface similarity is meaningful than to assume it is not. Another reason for us to be oblivious to many similarities is perhaps understandable given the large size of our everyday knowledge-base. For an animal
} 


\section{A Functional Architecture of Invariance}

Further supporting the present hypothesis of an evolutionary neurologically based invariance function subserving "analogical" access and and a resolution to Plato's learning paradox, comes from adapting the theoretical work of Pribram (1974, 1986, 1988). Invariance relations are fundamental to Pribram's theory that on a basic cellular level the brain functions as a spectral frequency analyzer. He indicates that individual cells and ensembles of cells fundamentally conform to certain mathematical functions called Fourier and Gabor transforms. Pertinent to transfer, these mathematical functions apparently involve the application of constants, identities, equalities, and associations, not discrete on/off functions found in many artificial intelligence programs.

According to Pribram, in such a brain, percepts and properties are selected from a primitive matrix in which frequency or spectral conjunctions abound. Everyday categories and objects are constructed by operations performed on this primitive frequency matrix. Largely responsible for the operations that convert the spectral domain to the everyday space-time domain of our experience (read: qualia) are dendritic micro processes (dendrites are kind of like connectors at the end of neurons) which function as cross correlational devices. And "cross correlations," explains Pribram (1974) "are a measure of similarity of two original images" (p. 429) More importantly he says, "a measure of similarity is precisely what is required for recognition" (p. 429, italics added) of the world as we know it. This is probably a good general description of how transfer is created and accessed on a spectral frequency level.

Moreover, Pribram explains that a cell's response is defined by a manifold of frequency averages not by simple identical features (i.e., surface or featural similarity). The sum of this manifold is constituted by that which remains invariant across the various processing stages or levels involved in the processing. The interesting and difficult problem, Pribram points out, is specifying the "transfer functions," the transformation codes involved in matching or correlating one code with another, or one level to another. Now, what this likely means is

having a large knowledge-base, seeing similarity everywhere, the costs of checking all events for their similarities would be prohibitive. Thus a conservative approach to seeing similarity may be reasonable. As we have seen above based on the work of Happel and Murre, the hidden structures of our brain may recognize many more regularities in the world around us than we have expected. To compensate for a massive recognition of similarity, through evolution the brain has evolved two different basic modes of responding to the world. The first is a pathway for rapid analysis of stimuli, the second a pathway for conducting a slower and more considered (learned) analysis. 
that lexical metaphor and analogical transfer are not fundamentally apprehended by composing or mapping concrete identical features or elements, as most computational research indicates but rather are generated by a featureless process of cross correlational frequency invariance among or between events. Pribram's account seems compatible with Happel and Murre's neurological architecture.

\section{Implications of an Evolutionary and Neurological Origin of Invariance Relations}

From the above perspectives, the phenomenal or everyday experience of concrete features of similarity and transfer are the end-state or final development or product of a more fundamental evolutionary and neurological process (see Haskell, 1989). Inversely, concrete similarity becomes only an access point, a stimulus activating micro neurological subprocesses of frequency analysis and cross correlations. In this kind of neurological systems, access would be gained by back propagation to the spectral matrix.

One of the implications of such a theory of invariance for analogical transfer seems to be that to improve the ability to access and apprehend equivalence or invariant transformations is to increase the extent to which the primitive spectral matrix is provided with a wide spectrum knowledge-base (see below). At this point, it should point out that the terms "access," and "representation" are, strictly speaking, metaphorical terms since nothing is being "accessed" or "represented."

\section{Analogical Progression}

Another implication derived from the neurological frameworks presented by Happel and Murre and by Pribram involves a potentially "new" and significant area of research which I have called analogical progression (Haskell, 1968a, 1978a, especially 2000a). Though analogical progression has been implicitly laying around the literature for over two thousand years, it has not been uniquely conceptualized by cognitive research. Aristotle wrote about what he called continuous analogy. The cognitive science research on analogical reasoning has yet to address this important higher order aspect of thinking and reasoning. ${ }^{9} 1$ originally modeled the concept of analogical progression after mathematical progression.

${ }^{1}$ The similar concept of continuous analogy has a long history in philosophy (Preus, 1970). According to Preus (personal communication, April 8, 2001), the concept is not original with Aristotle but is fundamental in Plato's work. He adopted the concept from the Pythagoreans, who apparently learned of it from the Egyptians. 
Arithmetically analogical progression is demonstrated as, $2: 4$ :: 4: 8 :: $8: 16:: 16$ : 32 , or 1 stands in relation to 10 that 10 stands to 100 , and 100 to 1000 , etc.. Again, in analogical form: $1: 10:: 10: 100:: 100: 1000$. The importance of analogical progression is not just in mathematics. Scientists, mathematicians, and other innovative thinkers often reason in progressing analogical forms of thought. One only has to look at the history of chemistry. Dmitri Mendeleev, the well known Russian chemist who discovered the periodic law and constructed the period table of the elements in 1869 is one such example.

He took the 63 elements that were known at that time, wrote the names and properties of the 63 elements on 63 separate cards, and stuck the cards on the wall of his laboratory. By carefully reexamining the data, sorting out the similar elements and pinning their cards next to each other on the wall, a discovery was revealed: he discovered that the properties were periodic functions of their atomic weights that repeated themselves periodically after each seven elements - a kind of analogy to the musical octave (do, re, mi, fa, sol, la, ti, Do'). From his ,,analogical transfer” table or structure, he was able by interpolation and extrapolation to then correct previous erroneous atomic weights of some elements. Perhaps more importantly, he was able to successfully predict three new elements from gaps in his octave-like periodic table.

It is also well known that John Newlands, an English chemist, anticipated by about three years Mendeleev's basic idea of the periodic law. The analogy with the musical octave was clear to him. Newlands read a paper at the English Chemical Society in which he compared the arrangement of the elements to the keyboard of a piano with its 88 notes divided into periods or octaves of eight. He said that the elements should be divided into octaves because each eighth element starting from a given one is a kind of repetition of the first, like the eighth note of an octave in music. He in fact called this the Law of Octaves. At the time, his use of the octave analogy was met with ridicule. The Law of Octaves was only accepted after Mendeleev completed his work five years later. The perception of musical octaves, where none of the notes are the same, yet which are perceived as the same, I suggest, is a form of analogical progression. ${ }^{10}$

\footnotetext{
${ }^{10}$ Recently, research by Bharucha, and Menci (1996) on the neurological mechanisms behind the recognition of octaves suggests that though octave equivalence is widely believed to be innate, it may not be octave recognition, qua octave, that is innate, but a particular learning mechanism responsible for it and other invariance transformations. They suggest ,that the first question can be addressed in terms of the perceptual learning of categories through neural self-organization. A general-purpose perceptual learning mechanism coupled with the acoustic regularities of the environment would not only enable octave equivalence to be learned but would compel such learning" (p. 142).
} 
Similarly, analogical progression can be exemplified by the following progressions. Atom : Molecule :: Molecule : Cell :: Cell : Organ : : Organ : Individual :: Individual :: Group; or Species : Genus :: Genus : Family :: Family : Order :: Order : Class, etc.

The question is, is there a neurological substrate for analogical progression? The answer is, probably. Revisiting Pribram's work, he suggests that during frequency analyses and cross correlations, neural cells respond to successive harmonics of a given base frequency (What this means is that a sound with a fundamental frequency of, say, $440 \mathrm{~Hz}$ (that is, the vibrations of an instrument repeat themselves 440 times each second) is actually a complicated oscillation that also contains a harmonic of $880 \mathrm{~Hz}$, another harmonic of $1,320 \mathrm{~Hz}$, and so on). This harmonic analysis capacity of cellular functioning, as Pribram - engaging in some analogical reasoning himself - points out, is isomorphic (i.e., something being structurally the same as) to an abstract transformation group in mathematics. This neurological harmonic form likely reflects the neurological basis of a higher order analogical reasoning, i.e., analogic progression

Finally, returning to the notion of intelligence being related to ability for analogical reasoning, transfer of learning, and mathematics, it may be as Platt (1962) suggested some time ago in another context, "Much, if not all, of what we call intelligence may be the ability to perceive successive analogies at higher and higher levels of abstraction, a multiple repetition of a single basic neural process of organization" (p. 115). Analogical progression would seem to be the higher order form of reasoning with invariant relations. Research needs to be conducted on this form of thought.

\section{A Knowledge-base Resolution to the Access Problem}

A final implication: As a long time member of what has become known as the knowledge Mafia (Brewer 1989), I will now suggest that what I have presented in this paper provides a kind of resolution to the analogical access problem and. ipso facto, to Plato's learning paradox. At least this resolution will be the closest we are likely to come to resolving the access problem. I suggest that the resolution lies in the quantity and quality of knowledge-base in the neurocognitive system (Haskell, 2000a).

While the importance of a large knowledge-base in thinking and reasoning would seem to be a traditional and commonsense position, only recently has its importance been resurrected. Unlike its original incarnation, cognitive research on knowledge-base now explains why and how knowledge-base is important in reasoning and problem solving (e.g., Singley and Anderson, 1989). Since the advent of artificial intelligence, emphasis had been on heuristics and strategies. 
For some time now in artificial intelligence there has been a reversal of this trend, especially in relation to expert systems. Still, as Ceci and Ruiz (1993) lament about their own emphasis on knowledge-base, "This view is likely to displease many of our cognitively oriented colleagues. But it does accord with recent thinking about neural networks" (p. 169).

If the dual model of the brain - one evolutionary based, hardwired and fast, and the other learning based and slower - as suggested by both the evolutionary and by neurological findings presented in this paper is correct, the implications seem clear for the importance of an appropriately encoded knowledge-base for accessing analogical/invariant relations. The knowledge-base resolution being presented is also based in part on a modified neural connectionist model (e.g., Rumelhart, 1989, Eskridge, 1994).

According to Happel and Murre (1994), their approach to understanding how the brain works offers advantages that other theories do not. For example, the Parallel Distributed Processing (PDP) approach, involving many of the current connectionist models of how neurological pathways work, relies on very little initial built-in structures. PDP systems are large networks of simple processing units, which communicate with each other by passing electrochemical messages back and forth. In this model, the processing units all work in parallel (or simultaneously) without a specific controlling command structure. In a PDP system, as Rumelhart notes (1989), "Knowledge resides only in its connections, and all learning involves a modification of the connections” ( $\mathrm{p}$. 299). In this kind of system, then, knowledge is not located in any particular place. Instead it's distributed throughout the entire brain. With each input added, i.e., knowledge, the distributed connections are reinforced. Thus the process of recognition is the consequence of a statistical process, of assessing probabilities regarding the input as to what it is.

Some of these PDP networks even assume a total interconnectivity between all neural nodes in the network. Others assume a hierarchical, multilayered structure in which each node in a layer is connected to all other nodes in neighboring layers of neurons. The advantage of such fully connected and distributed systems - but low in built-in initial structure - is that they are extremely flexible. Given enough resources e.g., sufficient neural nodes and time, any input and output mappings can theoretically be appropriately encoded and processed. While for many situations having total connections among the nodes is a desirable characteristic, there is a downside: When learning large scale tasks "from scratch," so to speak, such networks may require an incredible amount of time and search resources as the number of iterations necessary for a network to reach convergence increases with the size of the network. Thus, as Happel and Murre note, implementation of such large systems becomes problematic. A more strategic system must have therefore biologically evolved. Herein lies the 
difference between Happel and Murre's neural modeling network and most PDP models. There is yet another more important difference.

Typical models of neurological networks, including connectionist models, tend to be based on a learning "metaphor," while Happel and Murre's model is based on biological evolution that works largely by a kind of built-in neural natural selection, not learning, a kind of neural Darwinism (see Edelman, 1987). Learning in this view is seen as "fine tuning" of the phylogenetically and ontogenetically established neural circuits. I suggest the implications are profound for analogical reasoning and access. For, again, as Happel and Murre (1994) note,

We propose that the initial architecture is not only important for rapid learning, but that it also induces the system to generalize its learned behaviour to instances not previously encountered. Generalization of learning may well be a principal function of much of the initial structure of the brain (p. 1000).

Happel and Murre conclude that

The combination of an initial architecture produced by evolution and experiencebased additional fine-tuning prepares the organism to function in an entire domain, rather than just the limited part of the environment to which it was exposed. If this is indeed an important underlying principle, we must conclude that the hidden structure of the brain may capture many more regularities of the world around us than we have expected so far (p. 1000).

What the marriage of a hardwired set of fast acting brain circuits to a connectionist model means is that with the increasing size of a knowledgebase there is an increase in patterns and an increase in the recognition and matching of patterns by the hardwired circuits. It is this overlap (or "weight" in connectionist terms) that creates mental associations and mappings of similarities of data by the invariance-generating circuits. With continued adding of knowledge, the "summation" strength of the overlaps or weights in the system are increased thereby increasing cross correlations and the probability that one piece of knowledge will retrieve or be recognized as like another.

The multiple connections in such a system allow much of the knowledge of the entire system to be applied to any given instance of an event or problem. Since no information resides in a specific place, individual units or brain cells may be destroyed but memories or concepts can continue to exist. Further, because of the massively distributed character of information in the system, decisions can be arrived at even if the relevant information turns out to be "noisy," incomplete, or approximate. As Gardner observes of connectionist models in general, "These properties seem closer to the kinds of search and decision organisms must carry out in a complex and often chaotic natural world" (p. 133). 
Applied to analogical reasoning and to the importance of knowledge-base, what this means is that with each added piece of knowledge the entire system is enhanced or made robust.

The main implication of a knowledge-base that is fed into such an evolutionarily evolved neurological system, independently described on different levels by Happel and Murre, Edelman, and Pribram is that as knowledge-base increases, it increases the probability of analogical access and transfer by the evolutionarily hardwired neurological circuits. Such a process would tend to generate equivalences or invariants that are increasingly complex and which are more sensitive to small but significant nuances. Hence, making possible spontaneous access and significant analogical transfer. This is congruent with what is known about experts versus novices, with the primary distinction being that the former's advantage is knowledge-base

Another implication of this two-phase knowledge-base paradigm of transfer is that since the brain is dealing with patterns and probabilities, significant analogues, or -in instructional terms - far transfer cannot be taught by simple heuristics and cookbook type strategies. As Johnson-Laird (1989) has suggested in another context, "There can be no tractable algorithm that is guaranteed to make profound analogies as a matter of course" (p. 328). Moreover, a widely recognized failure to demonstrate spontaneous accessing of analogues is ubiquitous in the literature.

The failure on the part of subjects to access invariance, then, may largely be a lack of an appropriate knowledge-base (again, appropriately encoded). Most of the computational research on analogies and isomorphs has been conducted with abstract and unfamiliar examples that subjects have little knowledge-base and thus the back propagation to the hardwired innate circuits fails to select or recognize "matching" patterns. Research with more ecologically valid data, like the excellent work by Brown and her colleagues (Brown and Campione,1984), has shown that the lack of analogical access and transfer by young children is not so much due to their developmental stage as to a lack of an appropriate knowledge-base. Her research clearly demonstrates highly competent analogical reasoning in young children as long as they possess the relevant knowledgebase required for understanding the relations used in an analogy. Brown's research with children can be seen as paradigmatic for the importance of knowledge base in general for accessing analogical relations.

In my reading of these findings, the requirement of a large knowledge base would, again like Happel and Murre's two stage process of "learning," one hardwired and fast and one slow - and compatible with Edelman and Fodor - increase the ability of a system to more accurately disregard irrelevant information and superficial similarities and/or to cancel them out in an averaging process based on probabilities. It is well accepted that the ability to disregard irrelevance 
is crucial in recognizing analogues amongst other data (Marr and Sternberg, 1986, Overings and Travers, 1967, Haskell, 2000).

Moreover, an evolutionary and neurological "wetware" view of analogical reasoning is more compatible with recent approaches to thinking which suggest that reasoning is based on pragmatic reasoning schemas (see, Wason, 1968, and Cheng and Holyoak,1989) and models (see, Johnson-Laird, 1983). as opposed to abstract rules and formal logic on which the now generally unsupported Formal Discipline theory of transfer of learning was originally based.

Finally, given the requirements of the evolutionary and neurological findings presented here, computational research on analogical reasoning look very much like a Ptolemaic model of analogical reasoning - useful and reliable for certain navigational purposes, but not a valid model of the way a wet-brain-centered reasoning works.

\section{A Four-Stage Model of Analogical Access and Transfer}

Based on the above evolutionary, neurological, and knowledge-base considerations, a four stage model for analogical access and transfer seems to suggest itself. Stage I involves input of a large (and appropriately encoded) knowledge-base. From the perspective of this paper, this stage is the most crucial because it provides for Stage II, which involves evolutionarily established fast hardwired neurological invariance "operations" on that knowledge-base, as well as for Stage III, which involves the implicit or nonconscious and slower learning operations that fine-tune the original invariance relations established in the previous stage. This stage may also involve non conscious mapping, matching processes Finally, Stage IV is where current models of computationlike mapping, matching, and alignment processes are consciously carried out.

While this paper suggests a realistic model of how analogical relations "similarity" or invariants are accessed, a final description would involve a precise empirical delineation of the exact hardwired circuits that generate invariance from the vast array of input patterns.

\section{References}

Asch, S., (1955). On the use of metaphor in the description of persons. In, Werner, H.

(Ed.). On Expressive Language, (29-38). MA: Clark University Press.

Ascher, R. (1961). Analogy in archaeological interpretation. Western Journal of Anthropology, 17, 317-325. Press.

Balaban, O. (1994). The paradox of the Meno an Plato's theory of recollection. Semiotica $98,265-275$. 
Bertalanffy, L. (1963). General systems theory. New York: George Braziller.

Bharucha, Jamshed, J. and W. Einar Menci. (1996). Two Issues In Auditory Cognition:

Self-Organization Of Octave Categories And Pitch-Invariant Pattern Recognition. Psychological Science, 7, 142-149.

Black, M. (1962). Models and metaphors. Ithaca, New York: Cornell University Press. Boom,

J. (1991). Collective development and the learning paradox. Human Development, 34, 273-287.

Brewer, W. E (1989). The activation and acquisition of knowledge. In: Vosniadou, S. and Anthony, A. (Eds.), (pp. 532-545) Similarity and analogical reasoning, New York: Cambridge University Press, p. 535.

Brown, A. L., \& Campione, J.C. (1984). Three faces of transfer: Implications for early competence, individual differences, and instruction. In M. Lamb, A. L. Brown, \& B. Rogoff (Eds.). Advances in developmental psychology (Vol. 3, pp. 143-192.) Hillsdale New Jersey: Erlbaum.

Calvert, B. (1974). Meno's paradox reconsidered. Journal of the History of Philosophy, 12 145152; Cambridge University Press.

Campbell, D.T. (1960). Blind variation and selective retention in creative thought as in other knowledge processes. Psychological Review, 67', 380-400.

Ceci, S, and Ruiz, A. (1993). Transfer, abstractness, and intelligence. In Detterman, D.K.; Sternberg, R.J. (Eds.). Transfer on trial: Intelligence, cognition, and instruction. (pp. 168191) Norwood, NJ: Ablex.

Cheng, P.W. ; Holyoak, K. J. (1989). On the natural selection of reasoning theories. Cognition, 33(3), 285-313.

Chernigovskaya, T.V .(1994). Cerebral lateralization for cognitive and linguistic abilities: neuropsychological and cultural aspects. Studies in Language Origins, 3, 55-76.

Chiarello, C. (1991). Interpretation of word meanings by the cerebral hemispheres: One is Not Enough In: Paula J. Schwanenflugel, et al. (Eds.). The Psychology of word meanings (pp. 251_278) Hillddale, New Jersey: Lawrence Erlbaum.

Chomsky, N. (1972). Language and mind. Harcourt, Brace, and World.

Clayton, M.C., and Hayes, L J. (1999). Conceptual differences in the analysis of stimulus equivalence. The Psychological Record, 49, 145-161.

Cooper, L. (1960). The rhetoric of Aristotle. New York: Appleton Century Crofts. Cummins,

D.D., and Allen, C. (Eds.). (1998). The evolution of mind. New York: Oxford University Press.

Dejong, G. (1989). The role of explanation in analogy; or, the curse of an alluring name. In: Vosniadou, S. and Ortony, A. (Ed.), (pp. 346-365). Similarity and analogical reasoning. New York: Cambridge University Press.

de Kerckhove, D. (1986). Alphabetic literacy and brain processes. Visible Language, 203), 274-293.

Dreistadt, R. (1968). An analysis of the use of analogies and metaphors in science, The Journal Of Psychology, 68, 97-116.

Edelman, G. M. (1987). Neural darwinism: the theory of neuronal group selection. Cambridge, MA.: Perseus Books

Edelman, G. (1992). Bright air, brilliant fire: On the matter of mind. New York: Basic Books. 
Eskridge, Thomas C. (1994). A hybrid model of continuous analogical reasoning. In: Holyoak, K. J. and Bamden, John, A . (Eds.). Advances in connectionist and neural computation theory. (Volume 2).(pp. 207-246). Ablex Publishing: Norwood, New Jersey.

Fernandez, J.W. (1991). Metaphor: The theory of tropes in anthropology. Stanford, CA.: Stanford University press.

Fodor, J. A. (1980a). Methodological solipsism considered as a research strategy in cognitive Psychology Behavioral and Brain Sciences, 3, 63-109. p. 65.

Fodor, J. (1980b). Fixation of belief and concept acquisition. In: Piattelli-Palmarini, M. (Ed.). Language and learning: The debate between jean piaget and Noam Chomsky. (pp. 143-162). Cambridge, M.A:Harvard University Press.

Gardner, H. (1985). The mind's new science:A history of the cognitive revolution. New York: Basic Books.

Gazzaniga, M. (1992). Nature's brain. New York: Basic Books.

Gentner, D. (1982). Are scientific analogies metaphors? In: Miall, D. s. (Ed.). Metaphor: problems and perspectives, (pp. 106-132. Sussex, England: Harvester Press.

Gentner, D. (1983) Structure mapping: A theoretical framework for Analogy. Cognitive Science,7. 155-170.

Gentner, D. (1988). Analogical inference and analogical access. In: Prieditis, A. (Ed.). Analogica. (pp. 63-88) Los Altos, CA: Morgan Kaufmann.

Gentner, D. (1989). The mechanisms of analogical reasoning. In: Vosniadou, S. and Anthony, A. (Eds.), (pp. 199-241) Similarity and analogical reasoning, New York: Cambridge University Press.

Gick, M. L. (1985). The effect of a diagram retrieval cue on spontaneous analogical transer. Canadian Journal of Psychology, 39, 460-466.

Gick, M. L. and Holyoak, K. J. (1980). Analogical problem solving. Cognitive Psychology, 12, 306-355.

Gick, M. L. and Holyoak, K. J. (1987). The cognitive basis of knowledge transfer. In: Cormier, S. M. and Hagman, J. D. (Eds.). Transfer of learning contemporary research and application (pp. 9-45). New York: Academic Press.

Goodman, N. (1952). On likeness of meaning. In: Linsky, L. (Ed.). Semantics and the philosophy of language. Urbana: University of Illinois Press.

Gould, S. J. (1977). Eternal metaphors of paleontology. In Hallam, (Ed.). Patterns of evolution: As illustrated by the fossil record (1-26), Amsterdam: Elsevier Pub.

Gould, S. J. and Lewontin, R. C., (1979). The spandrels of San Marco and the panglossian paradigm: A critique of the adaptationist programme. Proceedings of the Royal Society of London, Series B, Vol. 205, No. 1161, p. 581-598.

Gray, S. S. (1991) Metacognition and mathematical problem solving. Journal of Developmental Education, 14, 24-28.

Green, T. F. (1979). Learning without metaphor. In: Ortony, A. (Ed.). Metaphor and thought. New York: Cambridge University Press. 462-473. (1956).

Happel, B. L. M \& Murre, J. M. J. (1994). Design and evolution of modular neural network architectures. Neural Networks, 7, 985, 1004.

Haskell, R. E. (2001).Cognitive science and the origin of lexical metaphor: A neurofunctional shift (NFS) hypothesis. Theoria et Historia Scientarium. 6, (forthcoming). 
- (2000a). Transfer of learning: Cognition, instruction, and reasoning. San Diego, CA. Academic Press.

- (2000b). Cognitive science, Vichian semiotics and the learning paradox of the Meno: Or what is a sign a sign of? In Perron, P, Sbrocchi, L. G., Colilli, P. \& Danesi, M., (Eds.). Semiotics as a bridge between the humanities and the sciences (336-370) Toronto: Legas Press.

- (1997). Review of: Mental leaps: Analogy in creative thought, by K. J. Holyoak and P. Thagard, 1995. Metaphor and Symbolic Activity, 12 (1) 89-94.

- (1991). An analogical methodology for the analysis and validation of anomalous cognitive and linguistic operations in small group (fantasy theme) Reports. Small Group Research, 22, 443-474.

- (1989). Analogical transforms: A cognitive theory of origin and development of equivalence transformation, Part I, \& II. Metaphor and Symbolic Activity, 4, 247 -277).

- (1987a). (Ed.), cognition and symbolic structures: The psychology of metaphoric transformation. Norwood, New Jersey: Ablex.

- (1987b). Giambattista Vico and the discovery of metaphoric cognition. In R.E. Haskell.

(Ed.). Cognition and symbolic structures: The psychology of metaphoric transformation, (pp.67-82) Norwood, New Jersey: Ablex.

- (1982). The matrix of group talk: An empirical method of analysis and validation. Small Group Behavior, 2, 419-443.

- (1978a). An analogic model of small group behavior. International Journal of Group Psychotherapy, 28, 27-54.

- (1978b). The structure of group talk: An analogic method of analysis. Doctoral Dissertation. The Pennsylvania State University.

- (1968a) Anatomy of analogy: A new look. Journal of Humanistic Psychology, 8, 161-169).

- (1968b). Toward a general theory of analogy: An interdisciplinary analysis. Masters Thesis. San Francisco State University).

Haslerud, G. M. (1972). Transfer, memory and creativity. Minneapolis: University of Minnesota Press.

Havelock, E. (1983).77te muse learns to write. New Haven,Conn: Yale University Press. Havelock, Eric (1963). Preface to Plato. Cambridge, MA: Harvard University Press. Hayek, F. A. (1952). The sensory order: An inquiry into the foundations of theoretical psychology. Chicago: University of Chicago Press.

Hesse, M., (1963). Models and analogies in science. New York: Sheed and Ward. Hoffding, H. (1905) On analogy and its philosophical importance. Mind, 14. 199-209. Hoffding, H. (1905) The problems of philosophy. [Tr. Galen M. Fisher, with Preface by William James] New York: Macmillan Co.

Hoffding, H. (1893) Outlines of Psychology. New York: Macmillan.

Hoffman, R.R. (1980). Metaphor in science . In: Honeck, R. P. and Hoffman, R. R. (Eds.). Cognitive psychology and figurative language (pp. 393-423) Hillsdale, New Jersey: Erlbaum Assoc.

Holyoak, K., and Thagard, P. (1995). Mental leaps: Analogy in creative thought. A Bradford Book, MIT Press. 
Holyoak, K .J. and Koh, K. (1987). Surface and structural similarity in analogical transfer. Memory and Cognition, 15(4), 332-340.

Holyoak, K. J. (1985). The pragmatics of analogical transfer. In: G.H. Bower (Ed.). The psychology of learning and motivation, (pp. 59-87) New York, Academic Press.

Holyoak, K. J., Junn, E. N. and Billman, D. O. (1984). Development of analogical problemsolving skills. Child Development, 55, 2042-2055. p. 2042.

Hummel J. E. and Holyoak K. J. (1997). Distributed representations of structure: A theory of analogical access and mapping. Psychological Review, 104 (3), 427-466.

Jerne, N. K. (1985, month) The generative grammar of the immune system. Science, 229:10571059.

Johnson-Laird, P. N. (1989). Analogy and the exercise of creativity. In Vosniadou, S.; Anthony, (Eds.). Similarity and Analogical Reasoning (pp.313-331) New York: Cambridge University Press.

Johnson-Laird, P. N. (1983). Mental models. Cambridge. MA: Harvard University Press.

Keane, M. (1987). On retrieving analogues when solving problems. The Quarterly Journal of Experimental Psychology, 39A, 29-41.

Kling, R. E. (1971). A paradigm for reasoning by analogy. Artificial Intelligence, 2, 147- -178.

Kimura, D. and Archibald, Y.(1974). Motor functions of the left hemisphere, Brain, 97. 1974, 337-350.

Koestler, A. (1967). The ghost in the machine. New York: MacMillan.

Kosslyn, S. M. and Koenig, O. (1995). Wet mind: The new cognitive neuroscience. New York: The Free Press.

Kuhn, T. (1970). The structure of scientific revolutions. Chicago: University of Chicago Press.

Lakoff, G. and Johnson, M. (1980). Metaphors we live by. Chicago: University of Chicago Press.

Leary, D. E., (1990). (Ed) Metaphors in the history of psychology. NY: Cambridge University Press.

LeDoux, J. (1996). The emotional brain. New York:Simon and Schuster.

Levi, E. H. (1949). An introduction to legal reasoning. Chicago: University of Chicago Press.

Lorenz, K. Z. (1974). Analogy as a source of knowledge. Science, 18 (July). 229-234. Luria,

A. R. (1976). Cognitive development: Its cultural and social foundations.

Cambridge, MA: Harvard University Press.

MacCormac, E. R. (1985). A cogntive theory of metaphor. Cambridge, MA: The MIT Press.

Marchant, G,, Robinson, J., Anderson, U. and Schadewald, M., (1991). Analogical transfer and expertise in legal reasoning. Organizational Behavior and Human Decision Processes, 48, 272-290.

Markman, A. B. \& D. Gentner. (1993). Structural alignment during similarity comparisons. Cognitive Psychology 25, pp 431-467.

Marr, D. B. and Sternberg, R. J., (1986). Analogical reasoning with novel concepts: Differential attention of intellectually gifted and nongifted children to relevant and irrelevant novel stimuli. Cognitive Development, 1, 53-72. 
McKeachie, W. J. (1987). The new look in instructional psychology: Teaching strategies for learning and thinking. In: De Corte, E, Lodewijks, H.. Parmentier, R. and Span, P. (Eds.). Learning and instruction Volume I (pp.443-456) Oxford: Pergamon Press.

Medin, D. and Ortony, A. (1989). Psychological essentialism. In: Vosniadou, S. and Anthony, A. (Eds.), (pp. 179-195) Similarity and analogical reasoning. New York: Cambridge University Press.

Moline, J. (1969). Meno's paradox. Phronesis, 14. 155-161.

Nash, H. (1963). The role of metaphor in psychological theory. Behavioral Science, 8, 336345.

Nickerson, R. S., Perkins, D. N, Smith, E. E. (1985). Problem solving, creativity, and metacognition. In R. S. Nickerson, D. N. Perkins, and E. E. Smith. (Eds.). The teaching of thinking, (pp. 64-110). Hillsdale, New Jersey: Lawrence Erlbaum Associates Publishing.

Oppenheimer, R. (1956). Analogy in science, American Psychologist, 11. 127-135. Ortony,

A. (Ed.). (1979). Metaphor and thought. Cambridge, England: Cambridge University Press.

Overings, R. L. R.; Travers, R. M. W. (1967). Variation in the amount of irrelevant cues in training and test conditions and the effect upon transfer. Journal of Educational Psychology, 58 62-68.

Pinker, S. \& Bloom, P. (1990). Natural language and natural selection. Behavioral and Brain Sciences 13 (4): 707-784.

Plato, Phaedrus (1956). (W. E. Great Dialogues of Plato. (Trans by W.H.D. Rouse) New York: New American Library.

Platt, John. (1962). Functional Geometry and the Determination of Pattern in Mosaic Receptors. Yearbook of the Society for General Systems Research. 7, 103-119.

Plotkin, H. (1998). Evolution in mind. Cambridge, M.A.: Harvard University Press. Polanyi, M. (1967). The tacit dimension. Garden City, N. Y: Doubleday.

Popper, K. R. (1987). Natural selection and the emergence of mind. In: Radnitzky, G.

\& Bartley, W. W. (Eds.). Evolutionary epistemology, rationality, and the sociology of knowledge, (pp.1 39-155). La Salle, Ill. Open Court Press.

Preus, A. (1970). The continuous analogy: The uses of continuous proportions in Plato and Aristotle. Agora, 1. 21-41.

Pribram, K. H. (1988). Brain organization and perception: Holnomic and structural determinants of figural processing. Mimeograph, manuscript, Stanford University.

Pribram, K. (1986). The cognitive revolution and mind brain issues, American Psychologist, 41, 507-520.

Pribram, K., Newer, M. \& Baron, R. (1974). The holographic hypothesis of memory structure in brain function and perception. In Krantz, D, Atkinson, R., Luce, R,, and Suppes, P. (Eds.). Measurement, psychophysics and neural information processing, (pp. 416-457) II. San Francisco, W. H. Freeman.

Pylyshyn, Z.W. (1979). Metaphorical imprecision and the "top-down" research strategy. In A. Ortony (Ed.). Metaphor and thought (pp.420-436). London: Cambridge University Press. 
Read, S. J. (1983). Once is enough: Causal reasoning from a single instance. Journal of Personality and Social Psychology, 45, 323-334.

Ricoeur, Paul, (1977). The Rule of metaphor: Multi-disciplinary studies of the creation of meaning in language. (Czerny, Robert, tr.), Toronto, University of Toronto Press.

Rips, L. J. (1989). Similarity and typicality, and categorizaion. In: Vosniadou, S. and Anthony, A.(Eds.), (pp.21-59) Similarity and analogical reasoning, New York: Cambridge University Press.

Rohatyn, D. (1974). Reflections on meno's paradox. Apeiron, 14, 69-73.

Rosch, E., and Mervis, C. (1975). Family resemblances: Studies in the internal structure of categories. Cognitive Psychology, 7, 573-605.

Rumelhart, D. E. ( $(9 W-))$.Toward a microstructural account of human reasoning. In: Vosniadou, S. and Ortony, A. (Eds.). Similarity and analogical reasoning, (pp. 298--312) New York: Cambridge University Press, p. 299.

Ryle, G. (1953). Categories. In A. Flew (Ed.). Language and Logic. Series 2, London: Oxford University Press.

Shanon, B. (1988). On the similarity of features. New Ideas in Psychology, 6, 307-321. Shanon,

B. (1984). Meno: A cognitive psychological view. British Journal of Philosophy of Science, 35, 129-147.

Schon, D. (1963). Displacement of Concepts. London: Tavistock Publications.

Shibles, W. (1971). Metaphor: An annotated bibliography and history. Whitewater, WL: Language Press.

Sidman, M. (1990). Equivalence relations: Where do they come from? In D. E. Blackman \& H. LeJeune (Eds.). Behaviour analysis in theory and practice. Contributions and controversies. Hillsdale, NJ: Lawrence Erlbaum Associates.

Skoyles, J. R (1984). Alphabet and the western mind. Nature, 309, 409-410.

Simon, H. (1976). Bradie on polanyi on the Meno paradox. Philosophy of Science, 43, 147-151.

Singley, M. K., and Anderson, J. R. (1989). The transfer of cognitive skill. Cambridge, Massachusetts: Harvard University Press.

Spellman, B. A. and Holyoak, K. J. (1992). If saddam is hitler then who is george bush? Analogical mapping between systems of social roles. Journal of Personality and Social Psychology, 62(6), 913-933.

Spencer, R. M. and Weisberg, R. W. (1986). Context-dependent effects on analogical transfer. Memory and Cognition, 14(5), 442-449.

Springer, S. P. and Deutsch, G. (1981). Left brain, right brain. San Francisco: W. H. Freeman.

Sternberg, R. J. and Rifkin, B. (1979a). The development of analogical reasoning processes. Journal of Experimental Child Psychology, 27, 195-232.

Sternberg, R. J., Tourangeau, R. and Nigro, G., (1979b). Metaphor, induction, and social policy: The convergence of macroscopic and microscopic views. In, Ortony, A. (Ed.). Metaphor and thought (pp. 325-353) NY: Cambridge University Press.

Sunstein, Cass, R. (1993). On analogical reasoning. Harvard Law Review, 106, 3, 741-791.

Thorndike, E.L. and Woodworth, R.S. (1901). The influence of improvement in one mental function upon the efficiency of other functions. Psychological Review, S. 247-261. 
Tourangeau, R., (1982). Metaphor and cognitive structure, In Miall, D.S. (Ed.). Metaphor: Problems and perspectives (pp. 14-35). NJ: The Harvester Press.

Tsoukas, H. (1993). Analogical reasoning and knowledge generation in organization theory. Organization Studies, 14, 323-346.

Vosniadou, S. (1989). Analogical reasoning as a mechanism in knowledge acquisition: A developmental perspective. In: Vosniadou, S. and Anthony, A. (Eds.). Similarity and analogical reasoning (pp. 413-437) New York: Cambridge University Press.

Wason, P. C. (1968). Reasoning about a rule. Quarterly Journal of Experimental Psychology, 20, 273-281.

Weimer, W. B. (1973). Psycholinguistics and Plato's paradoxes of the Meno. American Psychologist, 28, 15-33.

Winston, P. H. (1978). Learning by creatifying transfer frames. Artificial Intelligence, $10147-$ 172. 